\title{
Fatigue behavior in the mechanism of the Speed Bumper by using the Finite element method
}

\author{
Sitthiphong Promdan ${ }^{1,}$, , Teetut Dolwichai $^{2}$ \\ School of Mechanical Engineering, Institute of Engineering, \\ Suranaree University of Technology, \\ Nakhon Ratchasima 30000, Thailand \\ 1Promdan1@gmail.com, ${ }^{2}$ prapun@sut.ac.th
}

\section{Keywords: FEM, Speed bumper, Renewable energy}

\begin{abstract}
In the nowadays scenario the fossil fuel sources are depleting. Energy is obtained by the conversion of energy into other. The renewable sources of energy become more popular. One such energy is explained in this paper. The number of motorcycle pass through Speed Bumper on the road is increasing every day. This present design of Speed Bumper is carried out using standard procedure and design consider the material properties of each component. Method using fatigue in the mechanism of the Speed Bumper. The linear motion is converted into circular motion using one way bearing and ratchet gear. The speed obtained is amplified by using a set of gear and passing flywheel. This amplified speed is used operate a generator to produce power. There are many suitable mechanisms to the most efficiency. The mechanism using the finite element method (FEM) for design, it's practical with model on computer software and then practical implementation.
\end{abstract}

\section{Introduction}

According to the unstable oil prices in the present, it is impossible to prepare for the transition energy precisely. Alternative energy such as wind or solar power has restrictions on the production of electricity. Wind power can be used when it has suitable speed. The solar energy is only available during the day, with enough intensity. Communities have the energy source that most people unexpected if it can be used as an alternative energy. This energy derives from motion of Speed Bumper. From number of motorcycles at gate way of sample location have 1000 its large quantities and continuously, at the time 11.30 am to $1.30 \mathrm{pm}$. This research study the possibility of producing electrical energy from the motion of speed bumper during the night. It proposes to convert linear motion into rotary motion [1-4]. The motion passing it to the flywheel and then the speed obtained is in turn amplified by using the set of gear and generator to produce electric current, and store in the battery. This research study will be the basis to develop a prototype of the next application in other communities.

\section{Finite element Modeling}

The finite element modeling of speed bumper design can be used for 2 parts as follow modeling of the speed bumper, finite element analysis (FEA).

\section{Modeling of speed bumper}

Modeling of speed bumper is constructed by SolidWork2015 program as shown in Fig.1. It consists of 3 main mechanisms and 11 parts. 


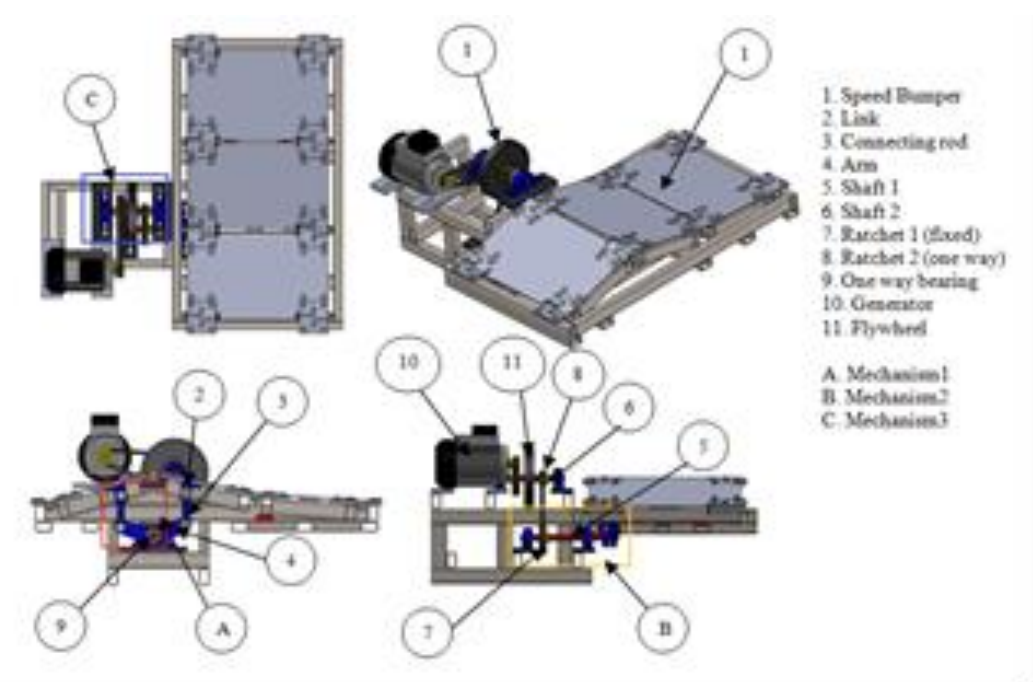

Fig. 1 Model parts of speed bumper

\section{The finite element analysis}

The model parts analysis are analyses with ANSYS Workbench version 15.0 with static structural and fatigue analysis the critical mechanism of the speed bumper. For good efficient of analysis of the mechanism, the simulation works are divided by 3 cases as shown in Fig.2.

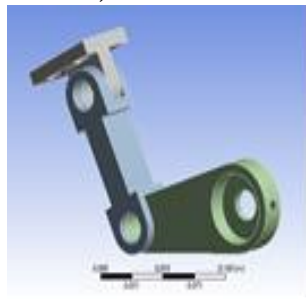

(a) Case I

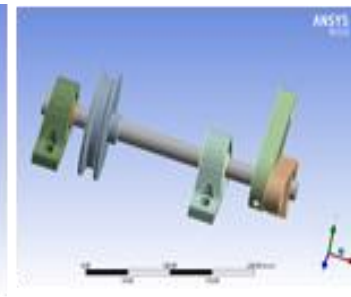

(b) case II

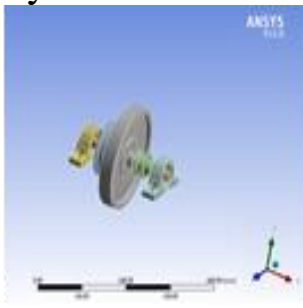

(c) case III

Fig. 2 Simulation case for speed bumper analysis

\section{Meshing}

All parts mechanism are meshes with solid elements with elements size as $10 \mathrm{~mm}$. Case I is meshed for 1635 elements, 3583 nodes, case II is mashed for 5207 elements, 11318 nodes and the last one, case III is meshed 6830 elements 14310 nodes.

\section{Boundary condition}

In the case I, applied the pressure loading on the link and transmitted through to the connecting rod to move by linear translation and transmitted to rotate the shaft number 1 by using the one way bearing. For the case II, applied the torsion that occurred by the case I to rotate the shaft number 2. And the last one, case III is manner similar as case II for power storage in the flywheel. All of the joint defined as revolute joint and contact of the parts are defined as bonded.

\section{Loading condition}

Loading condition is a for the case I is applied force size 1079.1 $\mathrm{N}$ at the upper link and join is fixed. Case II, applied the same load as the Case I on the arm and the bottom area of the box bearing are fixed. And the last one, case III applied the torsion size $323.73 \mathrm{~N}-\mathrm{m}$ at the ratchet number 2 and bottom are of the box bearing are fixed as shown in Fig.3. 


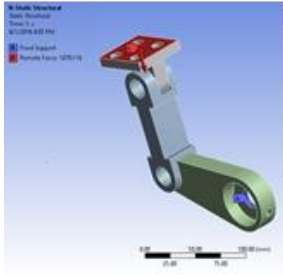

(a)

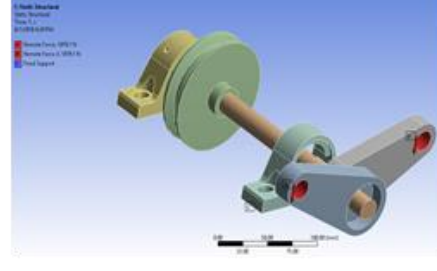

(b)

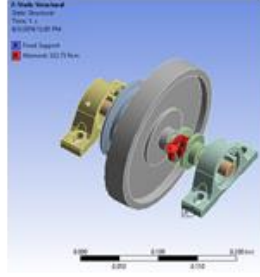

(c)

Fig. 3 Loading Condition for (a) Case I, (b) Case II and (c) Case III

\section{Material properties}

The material properties is applied for steel AISI 1020[1]. All of its properties are shown in Tab.1, and the S-N curve as shown in Fig 4.

Table 1. Properties of Steel AISI 1020.

\begin{tabular}{|c|c|c|}
\hline \multicolumn{2}{|l|}{ Properties } & $\begin{array}{c}\text { Condition } \\
\mathrm{s} \\
\end{array}$ \\
\hline Density $\left(\times 1000 \mathrm{~kg} / \mathrm{m}^{3}\right)$ & $77-8.03$ & 25 \\
\hline Poisson's Ratio & $0.27-0.30$ & 25 \\
\hline Elastic Modulus (GPa) & $190-210$ & 25 \\
\hline Tensile Strength (MPa) & 394.7 & \multirow{4}{*}{25} \\
\hline Yield Strength (Mpa) & 294.8 & \\
\hline Elongation (\%) & 36.5 & \\
\hline Reduction in Area (\%) & 66.0 & \\
\hline Hardness (HB) & 111 & 25 \\
\hline Impact Strength $(\mathrm{J})$ & \multirow{2}{*}{123.4} & \multirow{2}{*}{25} \\
\hline$(\operatorname{Izod})$ & & \\
\hline
\end{tabular}

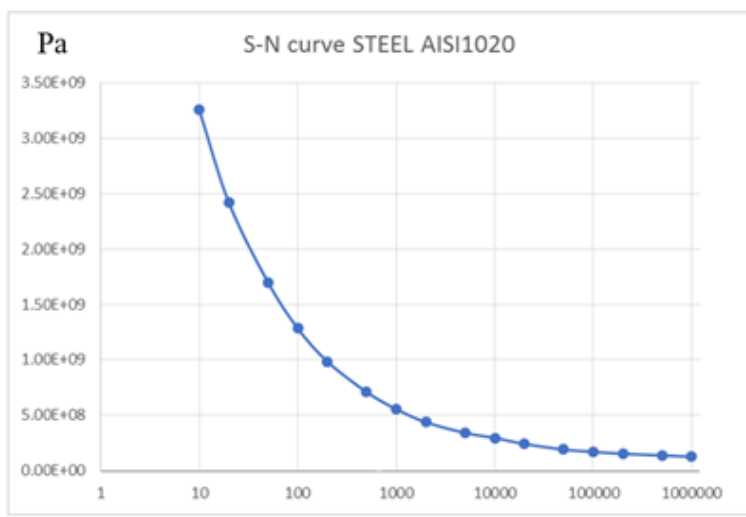

Fig. 4 S-N curve of the Steel AISI1020

\section{Simulation results}

According to the simulation results as shown in Fig. 5 (a-f) which shown the fatigue analysis of speed bumper mechanism for a constant amplitude type of loading with Goodman Criteria by zero based loading stress. Case I for Fig. 5 (a-b), the maximum equivalent stress equal to 52.34 Mpa with 3.5918 safety factor. The arm is the critical part. Case II for Fig. 5 (c-d), the maximum equivalent stress equal to $47.71 \mathrm{Mpa}$ with 3.9404 safety factor and the critical point is the same location of the case I. Case III for Fig. 5 (e-f), the maximum equivalent stress equal to 57.82 Mpa with 3.2513 safety factor. In this case, the ratchet part is critical part. 


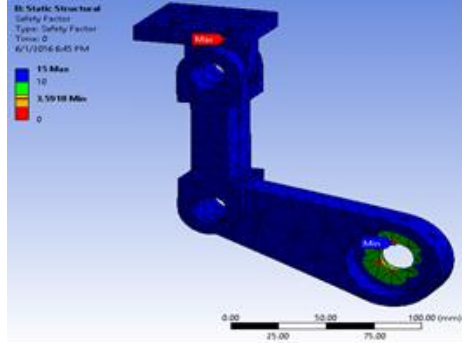

(a)

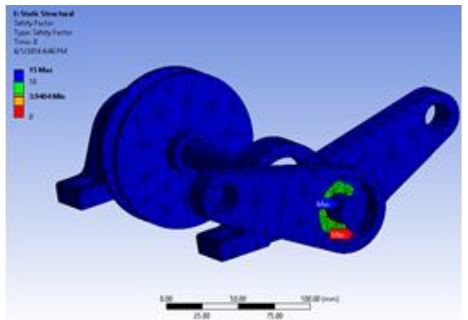

(b)

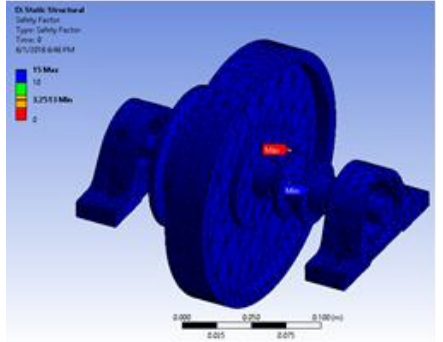

(e)

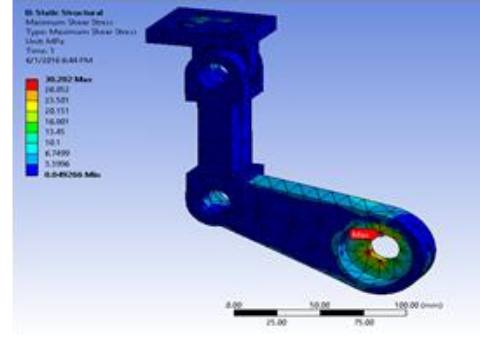

(b)

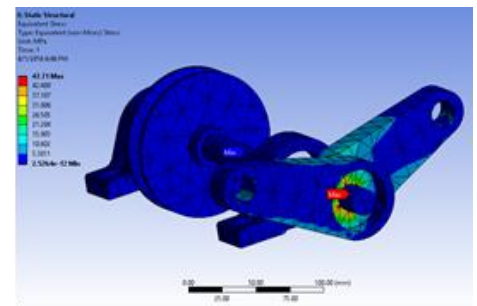

(d)

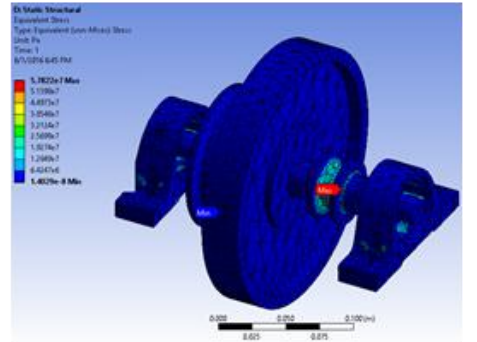

(f)

Fig.5 Simulation results (a-b) safety factor and equivalent stress for case I, (c-d) Safety factor and equivalent stress for case II, (e-f) safety factor and equivalent stress of case III

\section{Conclusions and Discussions}

The fatigue analysis of the mechanism of the speed bumper with zero based loading as 1000 million cycles can be summarized as follows; the critical part that is the first part considered to be damaged is ratchet number 2 . All mechanism can be used until reach the 1000 million cycles. However, the fatigue behavior can be described the critical part consideration before real construction.

\section{Acknowledgements}

The author is grateful for the financial support OROG scholarship from Suranaree University of Technology.

\section{References}

[1] A.Padma Rao, A.Kiran Kumar, S.Suresh. Power Generation from Speed Breaker by Rack and Ratchet Mechanism, International Journal of Current Engineering and Technology, Special Issue-2, (2014).

[2] D.Venkata Rao, K.Prasada Rao, S.Chiranjeeva Rao, R.Umamaheswara Rao, Design and Fabrication of Power generation System using Speed Breaker, International Journal of Current Engineering and Technology, Vol.4, No.4, (2014).

[3] Md.Saiful Islam, Syad Khalid Rahman, Jakeya sultana Jyoti, International Journal of Engineering Science and Innovative Technology, Vol.-2, Issue-3, (2008).

[4] Alok Kummar Singh, Deepak Singh, Madhawendra Kumar, Vijay Pandit, Prof.Surendra Agrawal, Generation of Electricity Speed Breaker Mechanism, International Journal of Innovative in Engineering and Technology, Vol. 2, Issue 2, (2013). 
[5] Larry J. Segerlind. Applied finite element analysis (2nd ed.). Michigan State University. (1984).

[6] efunda.AISI1020[Online].Available:http://www.efunda.com/materials/alloys/carbon_steels /show_carbon.cfm?ID=AISI_1020\&show_prop=all\&Page_Title=AISI\%201020, (2016).

[7] Auto FEM. Analyzing Results of the Static Analysis Study [Online]. Available:

http://www.autofemsoft.com/en/autofem-products/fatigue-analysis.html?start=1, (2016). 